\title{
Innovative methods for the removal, and occasionally care, of pressure sensitive adhesive tapes from contemporary drawings
}

\author{
Antonio Mirabile ${ }^{1 *} \mathbb{C}$, David Chelazzi ${ }^{2}$, Pamela Ferrari ${ }^{2}$, Costanza Montis ${ }^{2}$, Debora Berti ${ }^{2}$, Nicole Bonelli², \\ Rodorico Giorgi ${ }^{2}$ and Piero Baglioni ${ }^{2}$
}

\begin{abstract}
Aged pressure sensitive tapes (PSTs) can compromise the integrity and readability of drawings and paper artworks. Typically, PSTs on contemporary artifacts are difficult to remove owing to degradation processes and to the intrinsic sensitiveness of paper, inks and dyes to the solvents and tools used in the traditional conservation practice. Alternatively, we provide here a critical overview and expansion on the use of two recently developed methodologies for the removal of PSTs, based on the confinement of cleaning fluids in retentive gels. Various combinations of PSTs backings and adhesives were addressed on paper mock-ups containing different types of artistic media (inks, dyes), monitoring the ability of a hydrogel and an organogel to gradually exchange, respectively, an oil-in-water microemulsion or diethyl carbonate through the PSTs backings, swelling the adhesive layers and enabling safe PST removal. It was shown that the two methodologies are complementary as they target the removal of tapes with different components. In all cases, selective tape removal was carried out without uncontrolled bleeding of inks or transport of dissolved matter through the paper matrix, thanks to the retentiveness of the gels. The two cleaning systems were then assessed on four completely different artworks on paper, where they proved to be versatile tools to remove aged PSTs, or readhere detackified tapes that were part of the original artwork. Overall, the two methodologies complement each other and allowed overcoming the limitations of traditional cleaning approaches.
\end{abstract}

Keywords: Pressure sensitive tapes, Gel, Microemulsion, Alkyl carbonate, Contemporary drawings, Conservation, Cleaning

\section{Introduction}

Historical evidence tells us that, after becoming commercially available in the late 1920s, Pressure Sensitive Tapes (PSTs) have been a common tool used in museums, archives and libraries for the repair, identification and protection of cultural heritage collections [1]. PSTs have a multi-layered structure composed of a pressure sensitive adhesive and a backing. Minor components include a release coat, ensuring easy unrolling of the tape, and a primer that enhances adhesion between the backing and

\footnotetext{
*Correspondence: antonio.mirabile@gmail.com

1 Paper Conservator, 75009 Paris, France

Full list of author information is available at the end of the article
}

the adhesive layer. Backing materials may include paper, fabric, cellophane, cellulose acetate, and oriented polypropylene, while adhesives include natural and synthetic rubbers, acrylic copolymers, and silicones [2-4]. The most detrimental and frequently encountered PSTs on paper artworks are masking tape and cellophane [2], both of which have natural and/or synthetic rubber-based adhesives that over time oxidize, change in consistency and color (PSTs start to yellow), and can also become oily and penetrate the cellulose substrate. In the final degradation stages, adhesives usually turn dark brown and can crystallize, becoming hard and brittle and losing their adhesive power; besides, components such as tackifying resins and plasticizers can migrate into the underlying
Springer Open

(c) The Author(s) 2020. This article is licensed under a Creative Commons Attribution 4.0 International License, which permits use, sharing adaptation, distribution and reproduction in any medium or format, as long as you give appropriate credit to the original author(s) and the source, provide a link to the Creative Commons licence, and indicate if changes were made. The images or other third party material in this article are included in the article's Creative Commons licence, unless indicated otherwise in a credit line to the material. If material is not included in the article's Creative Commons licence and your intended use is not permitted by statutory regulation or exceeds the permitted use, you will need to obtain permission directly from the copyright holder. To view a copy of this licence, visit http://creativeco mmons.org/licenses/by/4.0/. The Creative Commons Public Domain Dedication waiver (http://creativecommons.org/publicdomain/ zero/1.0/) applies to the data made available in this article, unless otherwise stated in a credit line to the data. 
paper fibers making them translucent. Occasionally these materials can affect contemporary inks such as ballpoint pen, felt-tip pen and printing inks, causing them to bleed, migrate and darken, thus modifying the readability and interpretation of the artworks. A new group of acrylicbased adhesives, which do not discolor appreciably, came on the market in the 1980s; however they are subject to cold flow, and penetrate into paper. According to $3 \mathrm{M}$ literature, acrylic adhesives are coated to the backing and pre-crosslinked [2]. This causes the adhesives to be poorly soluble in most of the solvents typically used in paper conservation (listed in Sect. "Conservation treatments"), as we observed in preliminary solubility tests; few solvents (e.g. tetrahydrofuran) are able to solubilize the adhesives, but the solubilized adhesives migrate in the paper substrate and stain it. Besides, in all cases the solvents produced bleeding and lateral spreading of inks. Overall, time and experience have shown that PSTs on paper can be disfiguring, damaging, and difficult (sometimes impossible) to remove.

Conservators are familiar with a variety of methods for removing PSTs, including mechanical cleaning and wet methods such as immersion, poultices, cotton swabs, and suction table. However each method has associated risks/ disadvantages that may produce undesirable changes such as skinning or bleeding of artistic media [5], tidelines, overcleaning, and further penetration of the adhesives into the cellulose fibers. In particular, limitation and control of tidelines is crucial on paper artworks, as this type of alteration is not always instantaneously visible. Tidelines occur when introduced moisture moves laterally through the paper fibres, carrying water or dissolved materials such as dirt, media, degraded size, short-chain cellulose oxidation and breakdown products, fillers and other additives. Transported materials concentrate at the wet/dry interface and remain there as moisture evaporates, leaving a discoloration halo, and in some cases initiating oxidative reactions that produce yellow-brown cellulose degradation products. Most removal methods involve the use of volatile and toxic organic solvents considerably hazardous to conservation professionals.

Given the lack of safe methods for the removal of PSTs, there is still the need for reliable cleaning systems. Research in the field of colloid and materials science has proved to be a fundamental framework to develop solutions for the cleaning of works of art [610]. We decided to tackle the complex issue of PSTs removal by designing two new methods based respectively on the use of: 1 . a hydrogel as a scaffold to confine an oil-in-water (o/w) nanostructured fluid [7]; 2. a polymeric organogel to confine diethyl carbonate (DEC) [8]. The two methods are complementary in that they use cleaning fluids with different properties, so as to allow a wide range of cleaning applications. The nanostructured fluid, named "EAPC" as it contains ethyl acetate and propylene carbonate besides water (more than $70 \% \mathrm{w} / \mathrm{w}$ ) and a surfactant, is a versatile $\mathrm{o} / \mathrm{w}$ fluid able to swell and detach synthetic polymer coatings [6]. DEC is a "green" polar aprotic solvent, part of the family of alkyl carbonates that constitute a valid alternative to esters and ketones in most applications [11-14], including the softening of natural and synthetic polymeric adhesives. In our previous works we showed that both methods are able to grant controlled release of fluids on paper and safe removal of PSTs without alteration of the artifacts, thanks to the retentiveness of the confining scaffolds. In the present contribution, we provide extensive assessment of the two methodologies in advanced cleaning scenarios with added difficulty, which served as a new testing ground for the methods. Such challenging cleaning case studies allowed us to extensively check the versatility and applicability of the two methodologies over a plethora of substrates (e.g. several different inked/dyed paper artworks), exploring the full potential and complementarity of the hydrogel and organogel loaded with different cleaning fluids. This led to further insight on the use of these systems use for the removal of PSTs, and allowed us highlighting the main applicative aspects useful to cultural heritage conservation professionals.

In particular, we aimed to: (i) assess the efficacy of the two cleaning systems, highlighting their complementary use on PSTs with different composition; (ii) assess their safe use on highly challenging inked paper artworks, with sensitive components and difficult working conditions (e.g. presence of PSTs directly on intricate motifs of sensitive dyes, or the removal of PSTs from inner hinges, with the impossibility to flatten the artwork), monitoring the properties of the treated paper substrates. Besides the scientific data, aspects related to conservation theory and professional code of ethics were also introduced. The methods were first assessed on paper mock-ups representative of actual paper artworks, monitoring the cleaning efficacy and possible alterations induced on the paper substrate. Then, we faced the removal of PSTs from four completely different artworks on paper, which provided new challenging case studies with added difficulty, or alternative uses of the gels: 1. a red ink contemporary sketchbook by the Brazilian artist Renato Bezerra de Mello (Recife 1960); 2. a four hands recto-verso drawing, with tempera on the recto, realized by the PortugueseFrench abstractionist Maria Helena Vieira da Silva (1908 Lisbon-1992 Paris), and a non-figurative watercolour on the verso by the American artist Helen Phillips (1913 Fresno CA-1995 New York); 3. a drawing by the pop art American artist Keith Haring (1958 Reading PA-1990 
New York); 4. a collage by the French artist Pierre Buraglio (1939 Charenton-le-Pont), belonging to the movement Supports/Surfaces.

\section{Experimental Chemicals}

2-Hydroxyethyl methacrylate (HEMA) (Sigma-Aldrich, purity $\geq 99 \%$ ), poly(vinylpyrrolidone) (PVP) (SigmaAldrich, purity $\geq 99 \%$ ), ethyl 2-methylprop-2-enoate (EMA) (Sigma-Aldrich, purity $\geq 98.5 \%$ ), 2,2'-Azobis(2methylpropionitrile) (AIBN) (Fluka, purity $>98 \%$ ). $\mathrm{N}, \mathrm{N}$-methylene-bis(acrylamide) (MBA) (Fluka, purity $\geq 99 \%)$. 2-(2-methyl-acryloyloxy)ethyl 2-methylacrylate (EGDMA) (Sigma-Aldrich, purity $\geq 99 \%$ ), and diethyl carbonate (DEC) (Sigma-Aldrich, purity $\geq 98.5 \%$ ) were used for the synthesis of gels. Sodium dodecylsulfate (SDS) (Sigma-Aldrich, purity $\geq 99 \%$ ), ethyl acetate (EA) (Sigma-Aldrich, purity $\geq 99.5 \%$ ), propylene carbonate (PC) (Sigma-Aldrich, purity $\geq 99 \%$ ), 1-pentanol (1-PeOH) (Merck, purity $\geq 98.5 \%$ ), and ultrapure water obtained from a Millipore MilliRO-6 Milli-Q gradient system (resistivity $>18 \mathrm{M} \Omega$ ) were used for the preparation of the EAPC nanostructured fluid. Fluorescent probes for confocal laser scanning microscopy (CLSM) experiments were Rhodamine B isothiocyanate (RhB ITC) and Coumarin6 (Cou6), both purchased from Sigma-Aldrich (purity $\geq 99 \%$ ). All chemicals were used as received.

\section{Preparation of the cleaning systems}

The nanostructured fluid "EAPC" is an o/w fluid prepared using ethyl acetate (EA) and propylene carbonate (PC) as dispersed organic phase. 1-pentanol (1-PeOH) and sodium dodecyl sulphate (SDS) are used, respectively, as co-surfactant and surfactant. The composition is as follows: $73.3 \% \mathrm{H}_{2} \mathrm{O}, 3.7 \% \mathrm{SDS}, 7 \% 1-\mathrm{PeOH}, 8 \% \mathrm{EA}$, $8 \%$ PC. EAPC preparation procedure, characterization and use for the removal of synthetic polymer coatings from artworks are reported in the literature [15]. The structure of EAPC has been fully characterized using small-angle neutron scattering with contrast variation [15], and the localization of each component in the fluid was determined. Nanosized ellipsoidal droplets (major axis $12.8 \mathrm{~nm}$ ) [15] mainly composed of EA are stabilized in a mixed continuous phase (water and about $20 \%$ PC) by SDS and 1-pentanol. PC is mainly located in the continuous phase, also partitioned at the micelle interface, and confers enhanced cleaning capacity thanks to its high dipole constant. For its use on paper artworks, EAPC was confined into hydrogels made of networks of poly(hydoxyethyl metacrylate) (pHEMA) semi-interpenetrated (semi-IPN) with polyvinylpyrrolidone (PVP). The preparation and characterization of the $\mathrm{p}(\mathrm{HEMA}) / \mathrm{PVP}$ hydrogels is reported in previous works [16]: essentially, $\mathrm{p}$ (HEMA)/PVP semi-IPN networks are obtained through the free radical polymerization, in aqueous medium, of HEMA, using AIBN as initiator and MBA as cross-linker, in the presence of PVP linear chains, which are physically embedded into the growing $\mathrm{p}$ (HEMA) network. These gels are particularly suitable for the cleaning of watersensitive artifacts (e.g. paper) thanks to their high hydrophilicity (water content $<70 \%$ ) and retentiveness, their transparency, and their mechanical stability that ensures the absence of gel residues on treated supports [16]. For applications on paper mock-ups, hydrogels were loaded with EAPC through immersion for at least $12 \mathrm{~h}$. It has been shown that these gels are able to behave as sponges, uploading EAPC without substantial alteration of the fluid and gel structure and functionality [17].

DEC was instead confined into PEMA-based organogels, which were prepared by radical polymerization of EMA solubilized in DEC; AIBN and EGDMA were added to the solution respectively as initiator and crosslinker. The gelation procedure is described elsewhere $[18,19]$. After gelation, gel sheets were immersed in DEC for $24 \mathrm{~h}$ in order to fully swell with the solvent. PEMA gels have high solvent content ( $>75 \%$ with DEC), high retentiveness, and good mechanical properties, which allow their feasible manipulation (avoiding gels residues on treated substrates) and the possibility of shaping them to exactly match the dimensions of PSTs that need to be removed [18].

The formulations used in this contribution were specifically targeted to the requirements of the reported case studies. Multipurpose formulations of p(HEMA)/ PVP-based hydrogels and o/w nanostructured fluids for the cleaning of works of art are commercially available under the brand of Nanorestore Gel ${ }^{\circledR}$ and Nanorestore Cleaning ${ }^{\circledR}$; organogels should be soon available under the same brand.

\section{Preparation and characterization of mock-ups}

The PSTs used in this study are commercially available tapes; PST types, acronyms, and supplier companies are listed in Table 1. The table also summarizes the most effective combinations of gels and cleaning fluids for the removal of the PSTs (see Sect. "Results and discussion" for details). The chemical composition of PSTs backings and adhesives was investigated by Attenuated Total Reflectance Fourier Transform Infrared spectroscopy (ATR-FTIR), performed directly on the tapes. A Thermo Nicolet Nexus 870 FTIR spectrometer with a Golden Gate diamond cell was used; spectra were collected with a mercury cadmium telluride detector (MCT, sampling area of $150 \mu \mathrm{m}^{2}$ ), averaging 128 scans in the 4000 $650 \mathrm{~cm}^{-1}$ range, with a spectral resolution of $4 \mathrm{~cm}^{-1}$. 
Table 1 Description of PSTs used for the preparation of paper artwork mock-ups

\begin{tabular}{|c|c|c|c|c|c|}
\hline PST & Acronym & Brand & Backing $^{a}$ & Adhesive $^{a}$ & Cleaning system ${ }^{b}$ \\
\hline Packing brown tape & BT & Tesa & Polypropylene & Acrylic & PEMA-DEC \\
\hline Filmoplast P & FPP & NESCHEN & Paper & Acrylic & $\mathrm{pHEMA} / \mathrm{PVP}+\mathrm{EAPC}$ \\
\hline Masking tape & MKT & Tesa & Coated paper & Natural rubber & pHEMA/PVP + EAPC \\
\hline Magic tape & MT & Scotch $3 \mathrm{M}$ & Cellulose acetate & Acrylic & $\mathrm{pHEMA} / \mathrm{PVP}+\mathrm{EAPC}^{\mathrm{c}}$ \\
\hline Ordinary tape & OT & Tesa & Polypropylene & Acrylic & PEMA-DEC \\
\hline Insulating tape & $\mathrm{IT}$ & Pirelli & Poly Vinyl chloride & Synthetic rubber & PEMA-DEC ${ }^{c}$ \\
\hline
\end{tabular}

a The composition of backings and adhesives was assessed with ATR-FTIR (see Sect. "Results and discussion")

b The most effective cleaning systems for each type of PST are indicated, i.e. where the controlled release of the cleaning fluid led to penetration of the backing and swelling/softening of the adhesive, which could be easily removed with no risks for the mockups/artworks

c In these cases, penetration of the fluid through the backing produced some alteration of the backing (see Sect. "Results and discussion" for details)

Table 2 Description of inks, dyes and media used for the preparation of paper artwork mock-ups

\begin{tabular}{llll}
\hline Color & Brand & Media & Acronym \\
\hline Blue & Bic, Cristal & Ball-point pen & B-BPP \\
Red & Bic, Cristal & Ball-point pen & R-BPP \\
Blue & Stabilo: pen 68 Art. No 68/22 & Felt-tip pen & B-FTP \\
Green & Stabilo Pen 68 Art. No 68/36 & Felt-tip pen & G-FTP \\
Pink Neon & Stabilo Pen 68 Neon Art. No & Felt-tip pen & PN-FTP \\
& 68/056 & Felt-tip pen & Y-FTP \\
\hline
\end{tabular}

The dynamics of the interaction between the DECloaded PEMA gels and model PSTs backings were studied by means of Confocal Laser Scanning Microscopy (CLSM). PSTs mock-ups were prepared by attaching the tapes onto glass slides. A Leica TCS SP2 instrument equipped with a $20 \times$ air objective was used. For fluorescent labeling, two different probes were used: DEC loaded within gels was labeled by equilibrating polymeric films in an $100 \mu \mathrm{M}$ DEC solution of Coumarin 6 (Cou6); PSTs adhesives were labeled by immersion in $10 \mu \mathrm{M}$ aqueous solution of Rhodamine B Isothiocyanate (RhBITC). The fluorescent probes Cou6 and RhBITC were respectively excited with 488 and $561 \mathrm{~nm}$ laser lines. Fluorescence signals were collected in the ranges 498-513 nm for Cou6, and 591-616 nm for RhBITC. The experimental setup was designed in order to mimic a real application: labeled PSTs were attached on a glass sample holder, and gels loaded with Cou6-labeled DEC were laid on them; each gel slice was cut to match the shape of the tape.

For the preparation of inked/dyed paper artwork mock-ups, a selection of contemporary inks $[20,21]$ (see Table 2) was applied on paper samples (A4 sheets, $80 \mathrm{~g} /$ $\mathrm{m}^{2}$, Fabriano Leonardo). Solubility tests on the inked mock-ups were carried out using EAPC and DEC either non-confined or uploaded in the gels. Droplets of the fluids were placed on the inks/dyes and let dry, while the pHEMA/PVP-EAPC and PEMA-DEC gels were applied on the surface (after removing the excess of EAPC or solvent from the gels surface with absorbent paper) for 5 min, followed by visual inspection of possible ink/dye bleeding and lateral spreading.

PSTs (reported in Table 1) were applied on the inked portions of paper mock-up samples, which were then aged for 2 months alternating cycles of thermal aging $\left(80^{\circ} \mathrm{C}, 4\right.$ days $)$, aging at high relative humidity $(\mathrm{RH}=80 \%$, $25^{\circ} \mathrm{C}, 2$ days), and photochemical aging (4 days). Thermal aging was carried out in an oven. The RH in the humidity chamber was kept constant using a glycerol aqueous solution $(51 \% \mathrm{w} / \mathrm{w})$. For the photochemical aging, a Neon Light Color 765 Basic daylight Beghelli Lamp was used $(160 \mathrm{~mW} / \mathrm{lm}, 380-700 \mathrm{~nm})$, placing the samples in a closed chamber at room conditions $\left(36{ }^{\circ} \mathrm{C}, \mathrm{RH} 40 \%\right)$, where the samples' surface was exposed to ca. 11,000 Lux of homogeneous illumination. These conditions are meant to accelerate the natural aging that would be experienced by objects on display in museums, where illuminations of 50-100 lx are typically used.

To investigate the effects of DEC on the paper substrate, Whatman ${ }^{\circledR}$ paper samples (without inks or PSTs) were treated with DEC, applying $40 \mu \mathrm{L}$ of solvent on paper disks of $5 \mathrm{~cm}$ diameter. The disks were then aged following the same procedure as detailed above. The characterization of the paper mock-ups treated with DEC was performed by ATR-FTIR (see above for experimental conditions), $\mathrm{pH}$ measurements, and differential thermogravimetry (DTG). For $\mathrm{pH}$ measurements, the regulations of the Technical Association of Pulp and Paper Industries (TAPPI) were adopted [22]. Cold extraction on paper samples was carried out by putting $125 \mathrm{mg}$ of samples (cut into small pieces) in $9 \mathrm{ml}$ of deionized water under stirring, at room temperature; the $\mathrm{pH}$ of the extracting water was read after $1 \mathrm{~h}$. DTG was performed to measure the pyrolysis temperature $\left(T_{p}\right)$ of cellulose, 
as an index of the degradation of cellulosic samples; a decrease in $T_{p}$ is typically observed when depolymerization and swelling of cellulosic fibers take place [23]. Analyses were performed on 5-7 mg of samples, using a SDT Q600 (TA Instruments) apparatus, increasing temperature up to $500{ }^{\circ} \mathrm{C}\left(10{ }^{\circ} \mathrm{C} / \mathrm{min}\right)$ in a nitrogen atmosphere $(100 \mathrm{~mL} / \mathrm{min})$. The reported $\mathrm{pH}$ and DTG data are the average of three repeats for each technique.

\section{Removal of PSTs}

The removal of PSTs from inked portions of the paper mock-ups was carried out by direct application of the gels onto the tapes. The excess of EAPC or solvent was removed form the gels surface as described above; then, the swollen gels were shaped with a scalpel to match the dimension of the PST, and applied on the samples for few minutes. After swelling/softening of the adhesive, the tape backing was peeled off using tweezers, and then adhesive residues were removed coupling the use of gels with gentle mechanical action (see the "Results and discussion" section for more details). The same application procedure was followed for the removal of PSTs from actual paper artworks.

2D FTIR imaging was performed on the paper mockups to check the presence of possible adhesives residuals after PST removal. A Cary 620-670 FTIR microscope, equipped with an FPA $128 \times 128$ detector (Agilent Technologies), was used. The spectra were recorded directly on the surface of the samples (or of the Au background) in reflectance mode, with open aperture and a spectral resolution of $8 \mathrm{~cm}^{-1}$, acquiring 128 scans for each spectrum. A "single-tile" analysis results in a map of $700 \times 700 \mu^{2}(128 \times 128$ pixels $)$, and the spatial resolution of each Imaging map is $5.5 \mu \mathrm{m}$ (i.e. each pixel has dimensions of $5.5 \times 5.5 \mu \mathrm{m}^{2}$ ).

\section{Results and discussion}

A dedicated research project offers a unique opportunity to document materials and conservation treatments of works of art beyond levels normally attainable in a conservation studio. Our research on PSTs removal involved different stages, as described before: the preparation and aging of mock-ups (inked/dyed paper artworks); the characterization of the main PSTs components; the assessment of the gels, loaded with cleaning fluids, for the removal of PSTs from the mock-ups; the assessment of the gels on real paper artworks. A range of analytical techniques was employed in the study, including $\mathrm{pH}$ measurements, ATR and 2D FTIR Imaging, DTG, and confocal microscopy.

FTIR-ATR allowed identifying the main components (i.e. adhesives and backings) of the six representative types of PSTs selected for this study (Figs. 1 and 2). Four

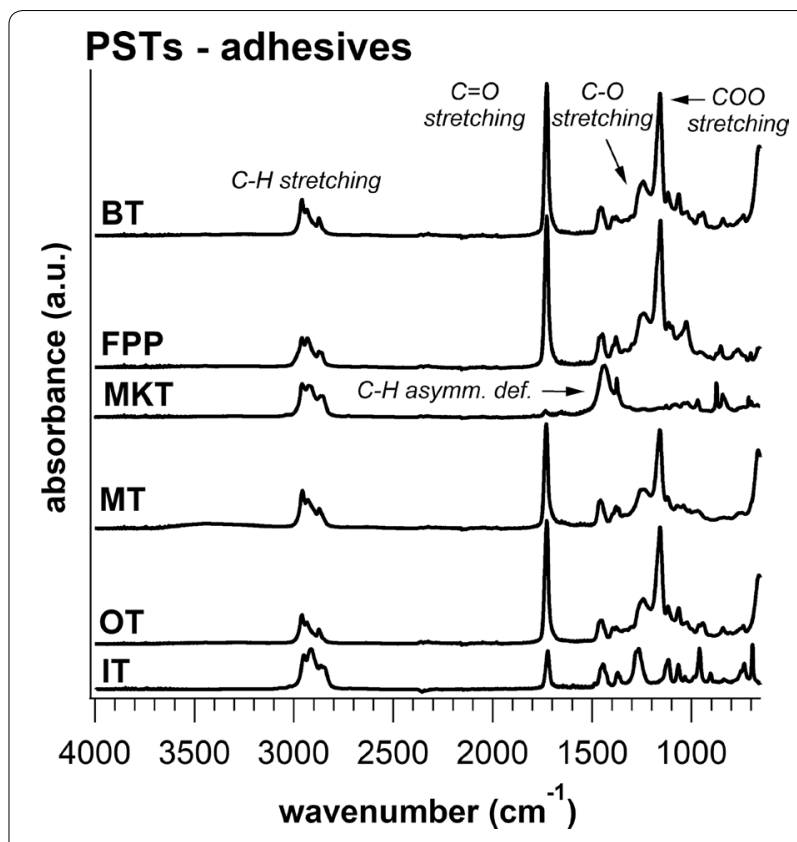

Fig. 1 ATR-FTIR spectra of the adhesive layer of selected PSTs: BT Packing Brown tape, FPP Filmoplast P, MKT Masking tape, MT Magic tape, OT Ordinary tape and IT Insulating tape

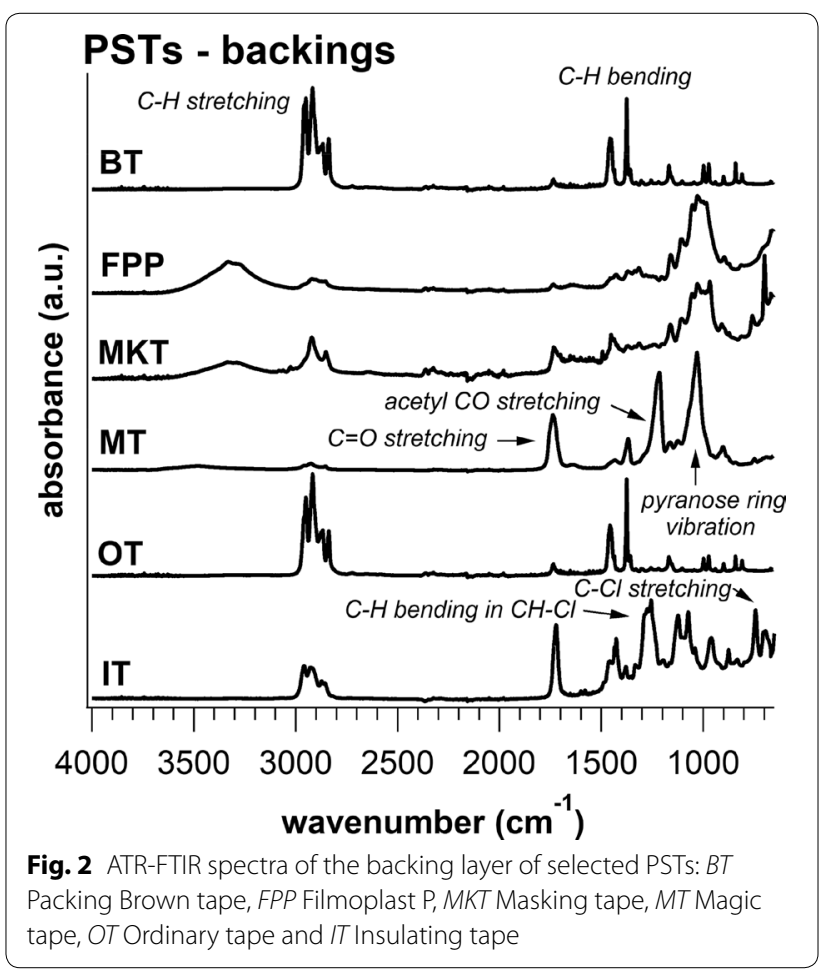

PSTs have acrylic-based adhesives, and two have rubberbased adhesives. Namely, the adhesive layers of Packing Brown Tape (BT), Filmoplast P (FPP), Magic Tape (MT), 
and Ordinary Tape (OT), all display infrared spectra typical of acrylate copolymers, with diagnostic peaks at about 1730 ( $\mathrm{C}=\mathrm{O}$ stretching of ester groups), 1240 (C-O stretching), and $1160 \mathrm{~cm}^{-1}$ (stretching vibration of ester group) [24, 25]; the adhesive of Masking Tape (MKT) was identified as a natural rubber due to IR absorptions at 2959, 2922, and $2860 \mathrm{~cm}^{-1}$ (CH stretching), 1437 and $1376 \mathrm{~cm}^{-1}$ (CH asymmetric deformation), $874 \mathrm{~cm}^{-1}$ (asymmetric stretching of $\mathrm{C}-\mathrm{O}-\mathrm{C}$ ), $844 \mathrm{~cm}^{-1}$ ( $\mathrm{CH}$ bending), and $713 \mathrm{~cm}^{-1}(\mathrm{CH}$ rocking) $[26,27]$; the spectrum of Insulating Tape (IT) shows a styrene-butadiene rubber with diagnostic peaks at 2916, 2844, 1449 , and $964 \mathrm{~cm}^{-1}$ ascribed to the butadiene segment, and absorptions of styrene at 1601 and $697 \mathrm{~cm}^{-1}$ [28].

Regarding the backings, Packing Brown Tape (BT) and Ordinary Tape (OT) shows the typical polypropylene infrared pattern with diagnostic peaks at 2950, 2916, 2865, and $2838 \mathrm{~cm}^{-1}$ (CH stretching modes), 1450 and $1375 \mathrm{~cm}^{-1}$ ( $\mathrm{CH}$ bending) [24, 25]; the spectra of Filmoplast P (FPP) and Masking Tape (MKT) backings show the characteristic profile of cellulose with bands between 2930 and $2850 \mathrm{~cm}^{-1}(\mathrm{CH}$ stretching), and a broad band centered at about $1000 \mathrm{~cm}^{-1}$ [29]; Magic Tape (MT) backing is made up of cellulose acetate, as evidenced by the presence of a strong peak at $1735 \mathrm{~cm}^{-1}$ ( $\mathrm{C}=\mathrm{O}$ stretching of the ester group) and typical bands at 1216 and $1031 \mathrm{~cm}^{-1}$ (respectively the $\mathrm{C}-\mathrm{O}-\mathrm{C}$ stretching of acetyl group and the $\mathrm{C}-\mathrm{O}$ stretching of pyranose ring) $[24,25,30]$; the spectrum of the Insulating Tape (IT) backing was assigned to polyvinylchloride backing owing to the presence of bands at 2915 and $2849 \mathrm{~cm}^{-1}$ $\left(\mathrm{CH}_{2}\right.$ stretching mode), $1426 \mathrm{~cm}^{-1}$ ( $\mathrm{CH}_{2}$ bending), 1329 and $1253 \mathrm{~cm}^{-1}$ (CH bending of $\mathrm{CH}-\mathrm{Cl}$ group), $960 \mathrm{~cm}^{-1}$ $\left(\mathrm{CH}_{2}\right.$ rocking), and $690 \mathrm{~cm}^{-1}(\mathrm{C}-\mathrm{Cl}$ stretching $)[31,32]$.

These PSTs compositions, summarized in Table 1, are in agreement with those reported in the literature.

Understanding the composition of the PSTs gave us indications on the type of cleaning fluids able to penetrate the backing and swell/soften the adhesive layer, which is essential to remove PSTs in a non-invasive way from paper artworks. Based on chemical affinity, the EAPC fluid is expected to efficiently penetrate paper and cellulose acetate backings, while poor interaction is expected with more hydrophobic backings. Instead, DEC is expected to diffuse hydrophobic polypropylene and polyvinyl chloride backings. In fact, using Confocal Laser Scanning Microscopy (CLSM), we demonstrated that EAPC, loaded in the pHEMA/PVP hydrogel, can penetrate across the hydrophilic paper-based backing of FPP without modifying it [33]; Fig. 3a-c shows that, after $20 \mathrm{~min}$, the green Rhodamine 110-labeled EAPC penetrates the backing, which is then homogeneously fluorescently labeled (Fig. 3c). The structure of EAPC is partially disrupted in the process, and a water-rich phase of the fluid reaches the bottom layer of the backing in contact with the adhesive. In the case of MT, after $20 \mathrm{~min}$, EAPC
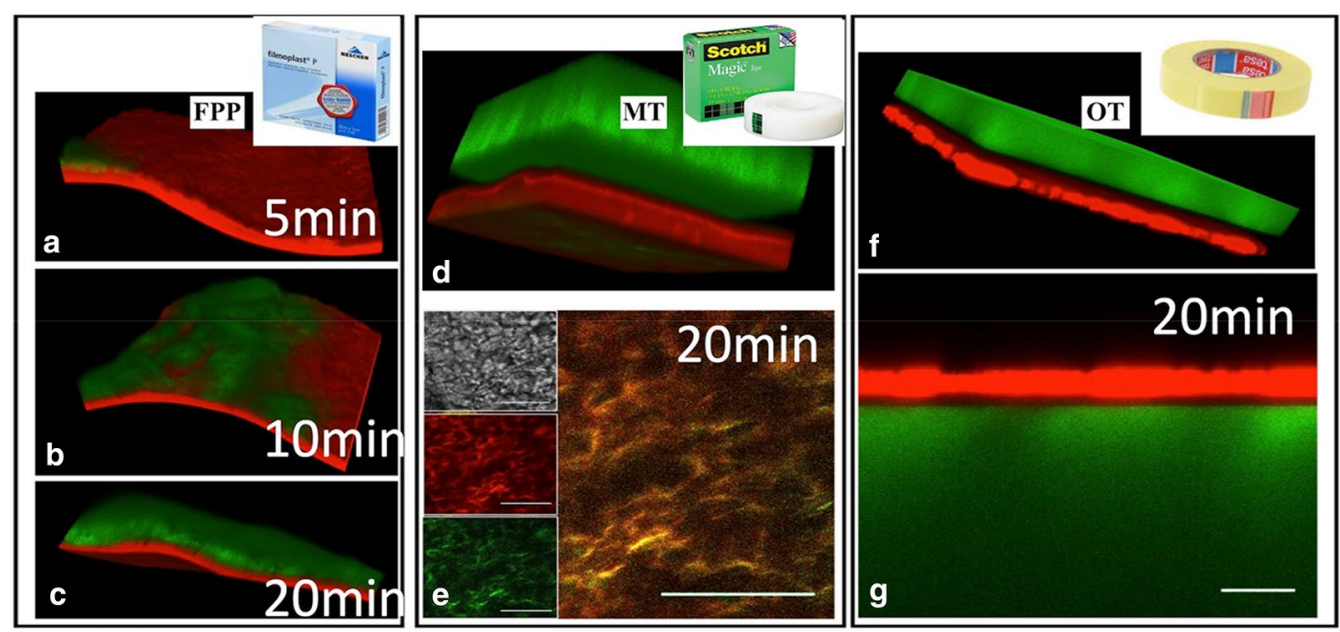

Fig. 3 pHEMA/PVP-EAPC hydrogel interactions with FPP, MT and OT PST adhesives viewed with confocal microscopy. EAPC is labeled green with Rhodamine 110 (Rh1 10), while the adhesive layers are labeled red with RhBITC. a FPP adhesive after 5 min interaction; $\mathbf{b}$ after 10 min; $\mathbf{c}$ after 20 min; due to the opacity of FPP backing, the hydrogel is not visible. $\mathbf{d}$ MT after 20 min of interaction; due to the transparency of the PST, both the initially unlabeled backing and the hydrogel are visible. e 2D horizontal section of MT adhesive after 20 min of interaction with EAPC: the red and green emissions, and the transmission (grayscale), are separately displayed in the small panels. $\mathbf{f} 3 \mathrm{D}$ reconstruction and $\mathbf{g} 2 \mathrm{D}$ vertical section of OT after 20 min of interaction. Due to the transparency of the PST, both the unlabeled backing and the hydrogel are visible. (Scale bars, $50 \mu \mathrm{m})$. Image readapted from Bonelli et al. Restoration of paper artworks with microemulsions confined in hydrogels for safe and efficient removal of adhesive tapes. PNAS. 2018 Jun;115(23):5932-5937 
from the hydrogel penetrates the cellulose acetate backing (the pale green region between the red adhesive and the bright green gel shown in Fig. 3d). Figure 3e shows a 2D horizontal section of the MT adhesive after 20 min of interaction with EAPC: the red and the green emissions are separately displayed (while the transmission is shown in grayscale); the overlay of these images (with colocalization of the probes appearing as yellow) highlights the successful penetration of EAPC in the upper parts of the MT adhesive. It was concluded that EAPC produces chemical modifications in the cellulose acetate MT backing (ethyl acetate probably solubilizes the diethyl phthalate plasticizer in cellulose acetate) and is absorbed inside the adhesive [33]. Remarkably, the confinement of the NFS inside the gel prevents alteration of the paper substrate, as opposed to the use of non-confined aqueous fluids that causes the introduction of moisture into paper fibers, and produces distortions and cockling [33].

On the other hand, EAPC is not able to efficiently interact with the polypropylene backing of OT [33]: as shown in Fig. 3f , g, after 20 min EAPC is separated from the adhesive layer by the backing, which remains unlabeled. In this case effective backing penetration and adhesive swelling was obtained with DEC [18], see Fig. 4. As expected, similar trends were observed for the interaction of EAPC and DEC with the backings of MKT (paper) and BT (polypropylene) considered in this study, while more insight was provided on the behavior of the polyvinyl chloride-based backing of IT.

Figure 4 shows the CLSM images acquired at different times on PEMA-DEC gels applied on the top surface of Ordinary, Brown, and Insulating PSTs (i.e. respectively OT, BT, and IT) lying on glass slides. DEC was labeled with green Cou6, the adhesives with red RhBITC, while the backing layer of the PSTs was not labeled and appears black in the images. In the CLSM instrumental setup, light is shone on the system from below; therefore, in the case of opaque PSTs backings (as for BT and IT) light stops at the backing level, and cannot reach the DEC-loaded gel, which appears black in the images. At time $t=0$, the red fluorescence of the adhesive is clearly observable, with no alteration caused by the solvent. In all cases, after 15-20 min, the solvent has penetrated through the backing, and the adhesive layers have become swollen with DEC, as also highlighted by their change in color from red to yellow-greenish hues. These results confirmed that $\mathrm{BT}$, having a polypropylene backing, displays a similar behavior than OT, with swelling of the acrylic adhesive layer in ca. 20 min of gel application. The images clearly show that also the polyvinyl chloride backing of IT allows DEC penetration, with significant swelling of the styrene-butadiene rubber adhesive after $15 \mathrm{~min}$ of application. It is worth noting that the
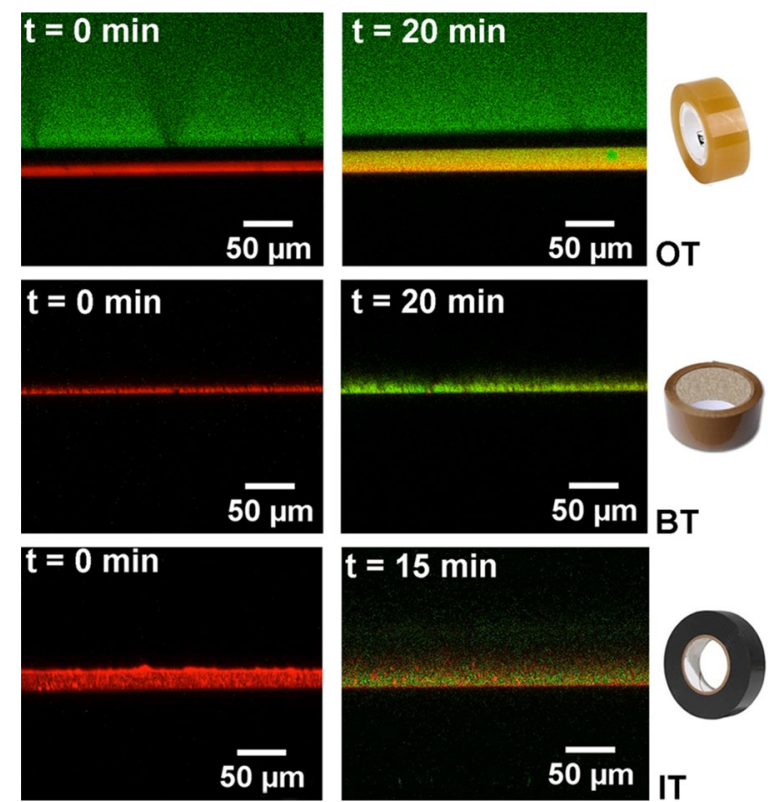

Fig. 4 Confocal Laser Scanning Microscopy (CLSM) images acquired at different times on PEMA-DEC gels applied on the top surface of Ordinary, Brown, and Insulating PSTs (i.e. respectively OT, BT, and IT). The DEC solvent is labeled green with Cou6, while the adhesive layers are labeled red with RhBITC. The PSTs backings are not labeled, and thus appear black. Because light is sent on the system from below, the DEC-loaded gel is visible only in the case of OT, where the PST is transparent and light passes through the backing, up to the gel. In the other cases, light stops at the backing and cannot reach the gel, which appears as black. At time $t=0$ the adhesive layer is well defined and not affected by DEC; after penetration of the solvent through the backing ( $t=15-20 \mathrm{~min}$ ) the adhesive layers become swollen with DEC, as also highlighted by the change in color from red to yellow-green

polypropylene backing is not macroscopically deformed after interaction with PEMA-DEC, even though some swollen areas were previously observed on the treated backing surface with Field Emission Gun Scanning Electron Microscopy (FEG-SEM) [18]. Instead, the polyvinyl chloride backing was visibly distorted and wrinkled after the application of the gel. The results of the applications of the gels and cleaning fluids on the PST mockups have been also summarized in Table 1.

Besides checking the ability of cleaning fluids to penetrate the PSTs backing, it was also fundamental to assess the behavior of the fluids in contact with graphic media typically found on paper artworks. Namely, the solubilizing power of EAPC and DEC towards a representative selection of inks and dyes (see Table 2) was tested, applying either droplets or gels loaded with the fluids (application time $5 \mathrm{~min}$ ). As shown in Fig. 5a, the direct application of non-confined EAPC led to solubilization and spreading of the graphic media; instead, the confinement of the fluid in the highly retentive $\mathrm{p}(\mathrm{HEMA}) / \mathrm{PVP}$ 


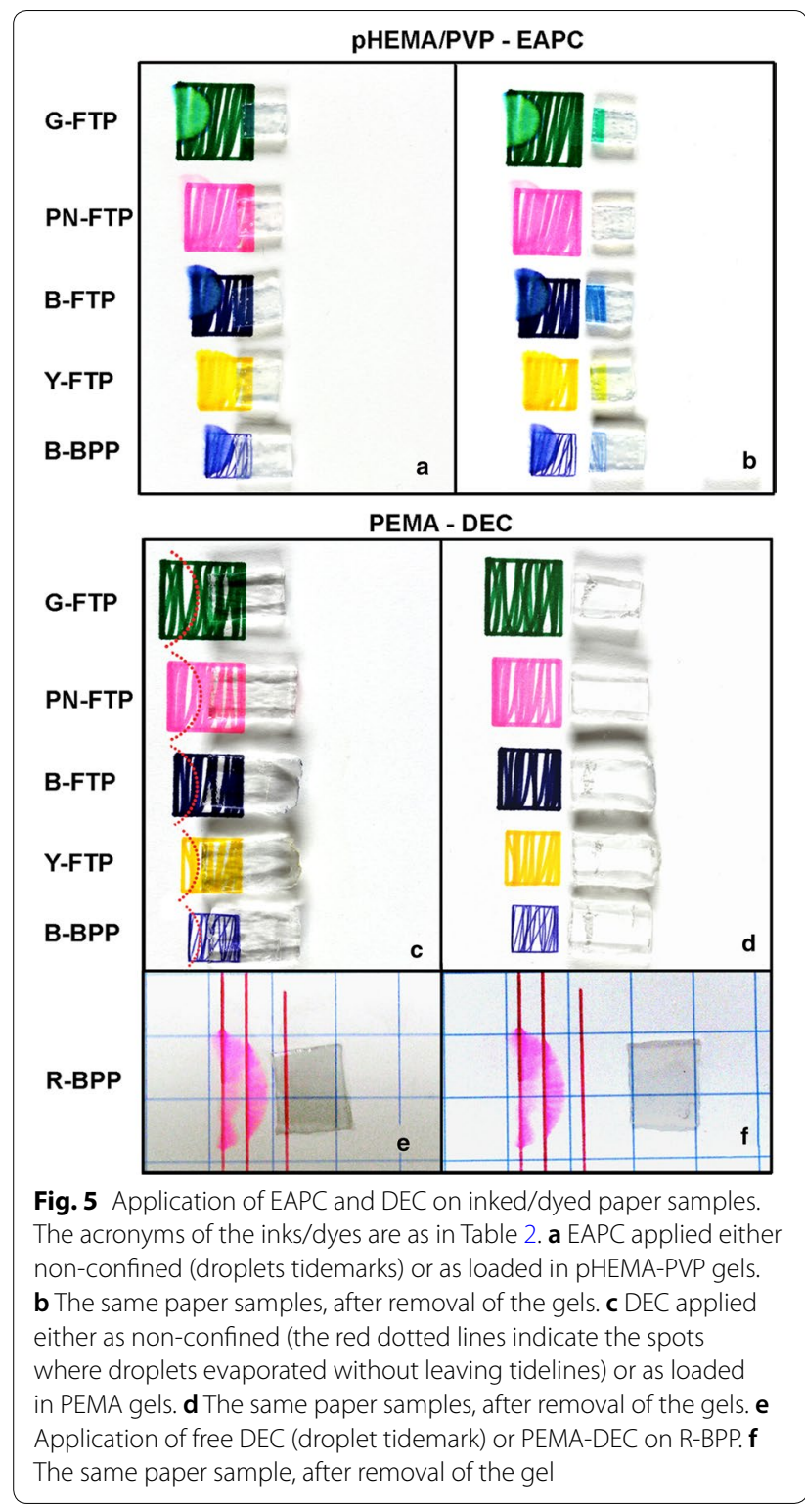

semi-IPN allowed its gradual release onto the inked/ dyed paper substrates, avoiding uncontrolled solubilization and lateral spreading. In some cases, extraction and migration of the dyes in the EAPC-loaded gel occurred, but without spreading of the dyes across the paper surface (Fig. 5b). DEC is inert to all the considered media, expect R-BPP, as shown by the absence of tidemarks or ink spreading in the spots where droplets of the solvent were applied (see Fig. 5c); no migration of the inks in the PEMA gel was observed (Fig. 5d). In the case of R-BPP, the free solvent causes spreading and tidelines (Figure E), but the confinement of the solvent in the PEMA gel effectively prevents the solubilization and spreading of the sensitive ink (Fig. 5e, f).
Because DEC is an organic solvent not commonly employed in the restoration practice, some further assessment regarded possible short- and long-term drawbacks related to its use on paper. Whatman ${ }^{\circledR}$ paper samples, treated with DEC, were analyzed by means of ATR-FTIR, DTG, and pH measurements, to assess possible paper degradation. Figure 6 displays the ATR-FTIR spectra of four Whatman ${ }^{\circledR}$ paper samples, i.e. pristine, treated with DEC, aged, treated with DEC and then aged. No alteration in the IR spectra of paper was observed following treatment with the solvent and aging. Likewise, no significant changes in the $\mathrm{pH}$ and cellulose pyrolysis temperature $\left(\mathrm{T}_{\mathrm{p}}\right)$ of the Whatman ${ }^{\circledR}$ samples were observed (see Table 3): as expected, the ageing procedure induced a small decrease in both $\mathrm{pH}$ and $\mathrm{T}_{\mathrm{p}}$, indicating a slight degradation, but no additional damage was induced on the paper fibers by DEC.

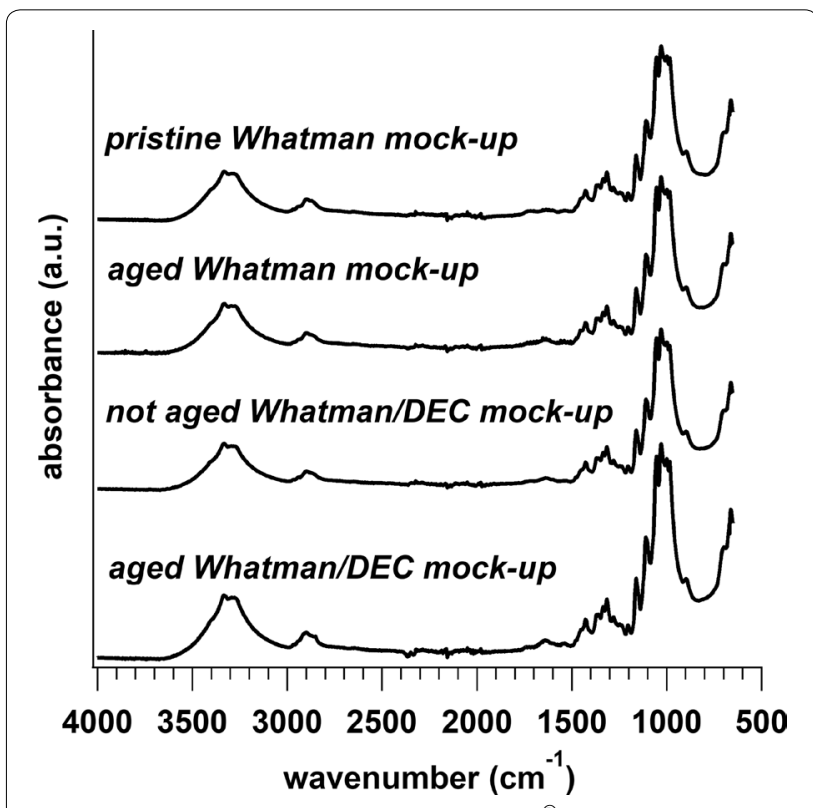

Fig. 6 ATR-FTIR spectra acquired on Whatman ${ }^{\circledR}$ paper mock-ups, either pristine or treated with $\mathrm{DEC}$, before and after accelerated aging

Table 3 Pyrolysis temperature $\left(T_{p}\right)$ and $\mathrm{pH}$ of Whatman ${ }^{\circledR}$ paper mock-ups, either pristine or treated with DEC, before and after accelerated aging

\begin{tabular}{|c|c|c|}
\hline Sample & $\mathrm{T}_{\mathrm{p}}\left({ }^{\circ} \mathrm{C}\right)$ & $\mathrm{pH}^{*}$ \\
\hline Pristine Whatman ${ }^{\circledR}$ & $365 \pm 2$ & 7.0 \\
\hline Aged Whatman ${ }^{\circledR}$ & $357 \pm 2$ & 6.6 \\
\hline DEC/not aged Whatman ${ }^{\circledR}$ & $363 \pm 2$ & 7.0 \\
\hline DEC/aged Whatman ${ }^{\circledR}$ & $357 \pm 1$ & 7.4 \\
\hline
\end{tabular}

*The error on $\mathrm{pH}$ measurements fell on the second decimal place, and was thus omitted 
The effectiveness of pHEMA/PVP-EAPC for the removal of tapes from paper artworks has been recently shown in some case studies, where MT and FPP PSTs were addressed [33], while PEMA-DEC was assessed on OT PSTs [18]. Here, the cleaning efficacy of the PEMADEC gel was further checked on an inked (B-BPP) paper mock-up with a BT PST, after aging of the mock-up. The gel was applied on top of the tape, which allowed the removal of the polypropylene backing; then, a successive application was carried out to swell, soften and remove the acrylate adhesive from the inked paper fibers. FTIR 2D Imaging was carried out on the inked surface before the application of the PST, after the removal of the backing, and after the final application of the gel. Figure 7 shows the IR maps obtained on the paper surface (the chromatic scale of the maps qualitatively shows the intensity of the band as follows: blue $<$ green $<$ yellow $<$ red). The use of the gel, coupled with gentle mechanical action, allowed the substantial removal of the adhesive, as indicated by the visual inspection of the fibers under visible light, and by the strong intensity decrease of the $\mathrm{C}=\mathrm{O}$ stretching band $\left(1735 \mathrm{~cm}^{-1}\right)$ of the acrylate adhesive in the IR maps. It must be noticed that the detection limit of FPA detectors is significantly lower than conventional MCT detectors for trace amounts of analytes heterogeneously distributed on a substrate. In fact, in this case localized analyte traces can be detected thanks to the high spatial resolution of the FPA detector [34]. In the visible light images, the slightly different hue of the cleaned area is due to the fact that fibers not coated by the PST were directly exposed to the light aging during the preparation of the mock-up, and thus experienced different photochemical degradation than those coated by the tape.

It must be noticed that, owing to the good mechanical properties of the pHEMA/PVP and PEMA gels, their application and removal do not leave detectable polymer residues on the treated surface, as previously verified on paper samples via ATR and 2D FTIR Imaging $[17,18]$.

\section{Conservation treatments}

Beside tests on mock-ups, the pHEMA/PVP-EAPC and PEMA-DEC systems were assessed in the present contribution on a selection of case studies, to further corroborate their use in the field of paper artworks conservation. The results obtained were critically compared with those previously achieved using these cleaning tools, so as to provide a complete overview on their efficacy and feasibility.

As a general premise, when approaching works of art on paper, conservation treatment decision-making is naturally carried out on a case-by-case basis, as the removal of adhesive tape residues from works on paper poses ethical and aesthetic questions. PSTs are typically removed only in case they have structurally damaged or pose a risk to the paper substrate, or if they have discoloured and therefore negatively affect the readability, interpretation and enjoyment of an object. Where possible, the examination and evaluation of the drawings involve three stages: firstly, the documentation of techniques and materials used by the artist; then, a thorough evaluation of the systems for PSTs removal; finally, the characterization of the removed tapes and the observation of the removal results.

Currently, the restoration practice foresees the use of aqueous systems (water and a $30 \%$ ethanol-water blend) and organic solvents such as ethanol, acetone, cyclohexane, ethyl acetate, tetrahydrofuran, toluene, xylene and $\mathrm{N}, \mathrm{N}$-dimethylformamide [2]. These fluids were tested as reference cleaning tools on the aged paper mock-up samples, using cotton swabs; as a matter of fact, they all caused, with the exception of cyclohexane, lateral migration of the inks and/or penetration of the adhesive into the paper fibers. Therefore, only the pHEMA/PVP-EAPC and PEMA-DEC systems were used in the case studies. Based on the data discussed in the previous paragraphs, pHEMA/PVP-EAPC was used to remove FPP (with cellulose-based backing), and MT (with cellulose acetate backing), while PEMA-DEC was used on OT and BT that feature polypropylene backings.

We worked on four contemporary works of art on paper: a red felt-tip pen (FTP) notebook by Brazilian artist Renato Bezerra de Mello, a tempera and watercolour recto and verso drawing by Maria Helena Vieira da Silva and Helen Philips Hayter, a black ink drawing by Keith Haring, and a painted collage by Pierre Buraglio.

\section{Renato Bezerra de Mello}

This case study was selected as it represents a challenging and advanced scenario, owing to some important characteristics. This series of Renato's artworks are drawn on a Moleskine ${ }^{\circledR}$ sketchbook, where each page is covered by small red FTP strokes composing concentric circles (Fig. 8). FTPs feature reservoirs with a core of absorbent material that serves as a carrier for the ink [35], which in turn can contain different formulations of dyes, solvents (e.g. ethanol, isopropanol) and additives such as $\mathrm{pH}$ modifiers, humectants, antifoaming agents, surfactants, biocides, fillers and extenders [36-40]. As a result, FTPs are among the most unstable artistic media, highly sensitive to photochemical degradation and to any kind of wet treatment. Luckily, in our case, De Mello's artwork was in very good conditions, but PSTs with paper backings were present on the gutter of three pages, covering part of the drawings (see Fig. 8b). The added complexity of this case study was thus the need to remove PSTs from an inked three-dimensional substrate (inside margins of 

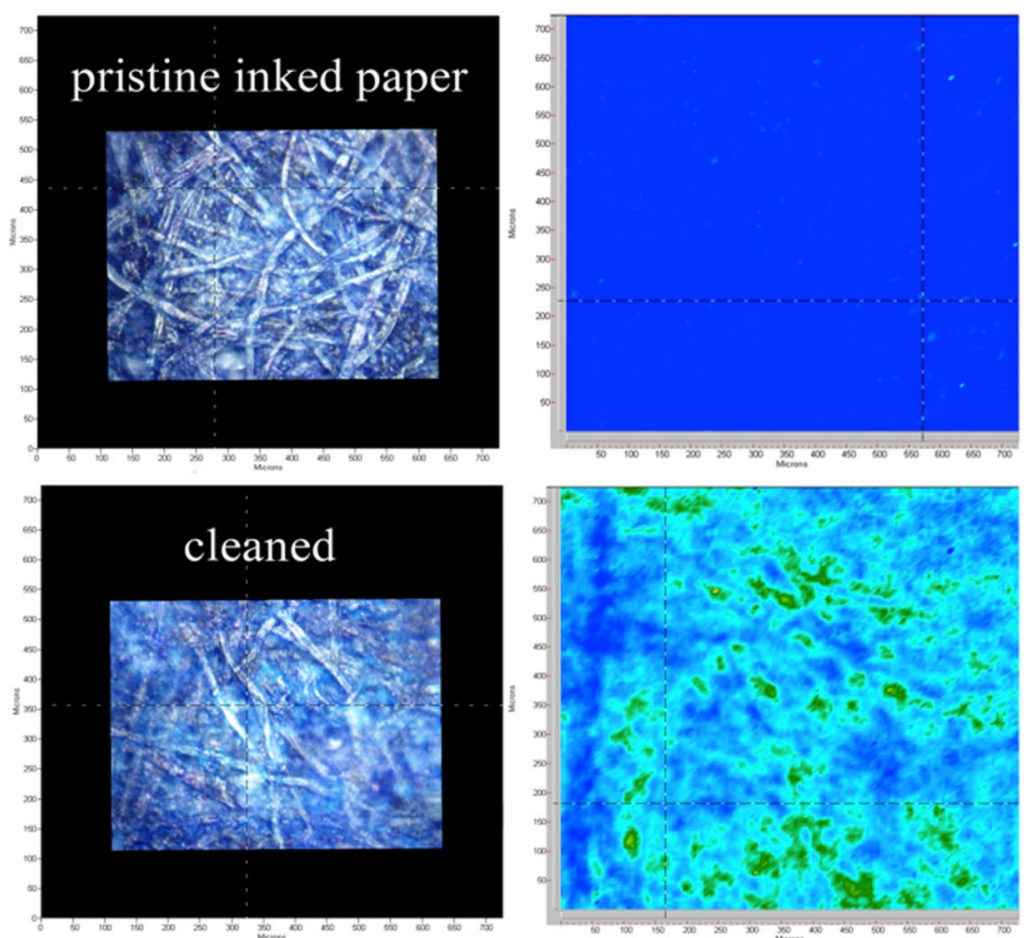

max Abs.
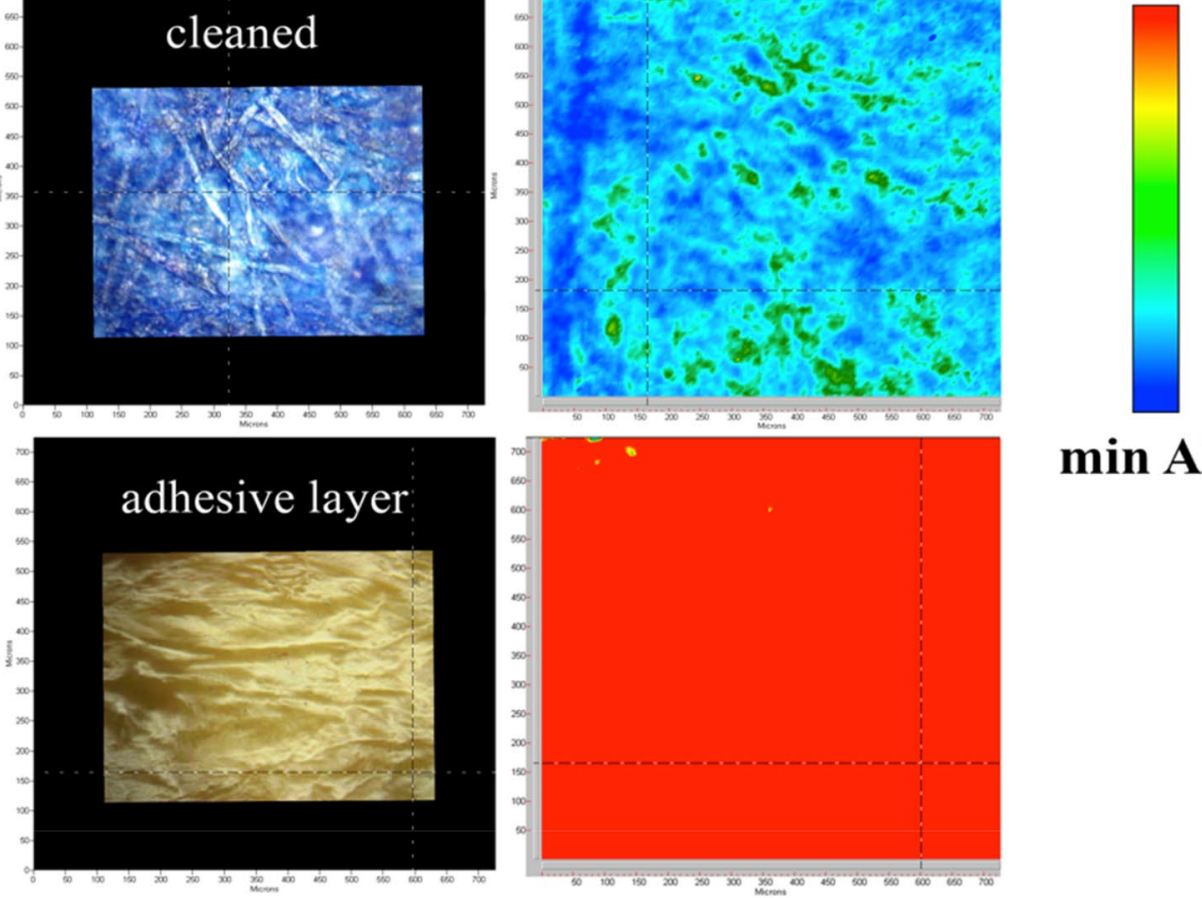

\section{$\min$ Abs.}

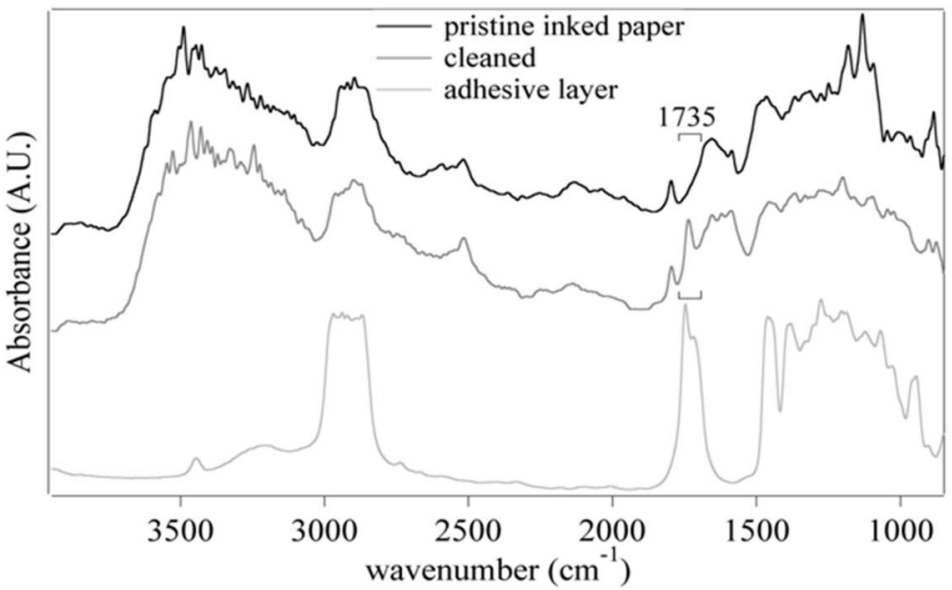

Fig. 7 FTIR 2D imaging of a Whatman ${ }^{\circledR}$ paper mock-up sample, featuring a B-BPP ink. (Top row) Pristine inked paper. (Center row) Area where the PST adhesive was removed using a PEMA-DEC gel. (Bottom row) Area where the adhesive was not removed. The corresponding FTIR maps $\left(700 \times 700 \mu^{2}\right)$ show the imaging of the band at $1735 \mathrm{~cm}^{-1}(\mathrm{C}=\mathrm{O}$ stretching of the acrylate adhesive). (Bottom panel) FTIR Reflectance spectra of the inked paper (pristine and after adhesive removal), and of the adhesive layer. Each spectrum relates to a single pixel $\left(5.5 \times 5.5 \mu \mathrm{m}^{2}\right)$ of the corresponding 2D Imaging map 

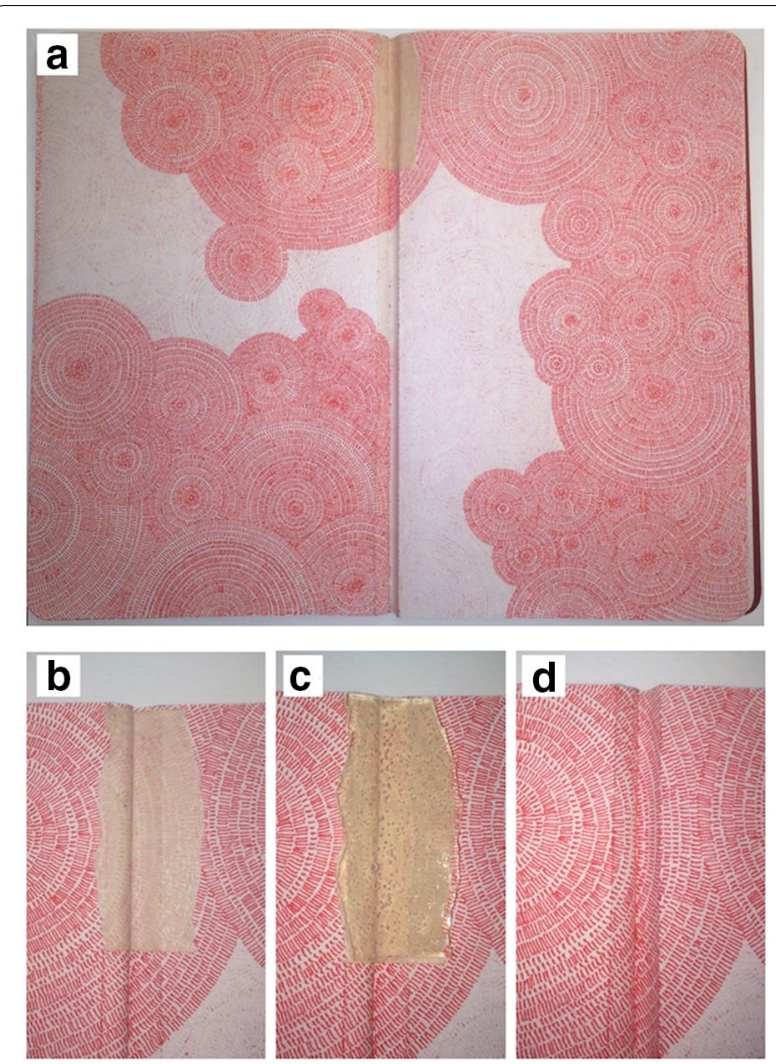

Fig. 8 c Renato Bezerra de Mello sketchbook, double page with a PST (with a paper backing) on the upper side; $\boldsymbol{b}$ detail of the PST; $\mathbf{c}$ a p(HEMA)/PVP gel, loaded with EAPC, lying on top of the PST to swell the adhesive; $\mathbf{d}$ detail of the same area after removal of the PST and adhesive

the notebook, close to the spine), without bleeding the extremely sensitive FTP ink: the minimal alteration of the FTP strokes would have caused severe aesthetic alteration on the intricate network of fine red lines. Besides, flattening the notebook was impractical, and the use of heat to remove the PSTs was discouraged owing to the risk of inducing migration of the adhesive into the paper fibres, which would then require potentially invasive abrasion with eraser gums. The possibility of working with flexible and retentive gels, able to adapt to the notebook three-dimensionality and to release cleaning fluids at controlled rate, was key to this cleaning intervention, which served as a testing ground to probe the use of the pHEMA/PVP-EAPC hydrogels in such difficult conditions.

The PSTs were easily identified as Masking Tapes (MKT), thanks to the presence of their characteristic creped paper backing [4]; these tapes typically contain natural or synthetic rubbers as adhesives (see also the FTIR analyses in Sect. "Results and discussion"). A set of solubility tests showed that the red ink is extremely sensitive to water and solvents. The safe and effective removal of the paper-based PSTs was thus performed with the following procedure: the pHEMA/PVP-EAPC hydrogel was cut to match exactly the size of the PSTs, and then applied on top of the PSTs. After $5 \mathrm{~min}$, the softening of the PST was tested with a scalpel. After $5 \mathrm{~min}$, the softened PST was detached with gentle mechanical action, using a scalpel, with no alteration of the red strokes or abrasion of the underlying paper support, and without leaving observable adhesive residues on the artwork. The successful application of the gels in this challenging case was deemed as a significant improvement over traditional cleaning methods.

\section{Vieira da Silva/Philips}

This artwork was realized by Maria Helena Vieira da Silva (recto side, tempera) and Helen Philips Hayter (verso side, watercolor). The paint media contain plasticizers (e.g. glycerin), humectants (sugar syrup or honey), wetting agents and preservatives, which overall makes the paints highly sensitive to water and solvents, discouraging the use of moisture and/or organic solvents for cleaning operations. The risk to cause staining and solubilisation of the media must be minimised, particularly in cases like this, where the paper substrate is thick and absorbing. In this case, it was necessary to remove two different types of repairs, i.e. brown paper-based and translucent PST hinges that had been used to attach the watercolor side to its old mount (see Fig. 9).

The PST was an MT tape with a cellulose acetate backing and acrylate-based adhesive, as confirmed by ATR analysis [33]. The removal of the PST hinge was realized with the pHEMA/PVP gel loaded with EAPC [33] and cut to match the tape profile. After 5 min the softening of the PST was tested with a scalpel, and then the PST was removed with gentle mechanical action with no loss of the underlying watercolour layer or abrasion of the artwork substrate.

The brown paper-based hinge represented a different challenge, which we discuss here as an expansion of the potential use of the pHEMA/PVP gels. These types of hinges have brown paper coatings and vegetal glue adhesives, in fact they are typically applied by humidification; therefore, it was expected that water, released at controlled rate at the coating-adhesive interface, could be able to swell the adhesive layer allowing the detachment of the hinge. In this case, the use of EAPC was deemed as non-necessary, also considering that the fluid is able to penetrate the paper coating easily and potentially access to the highly sensitive paint media. Therefore, in this case it was decided to apply the p(HEMA)/PVP gel simply loaded with water. The hinges were removed with $5 \mathrm{~min}$ application; the moisture of the hydrogel slowly 


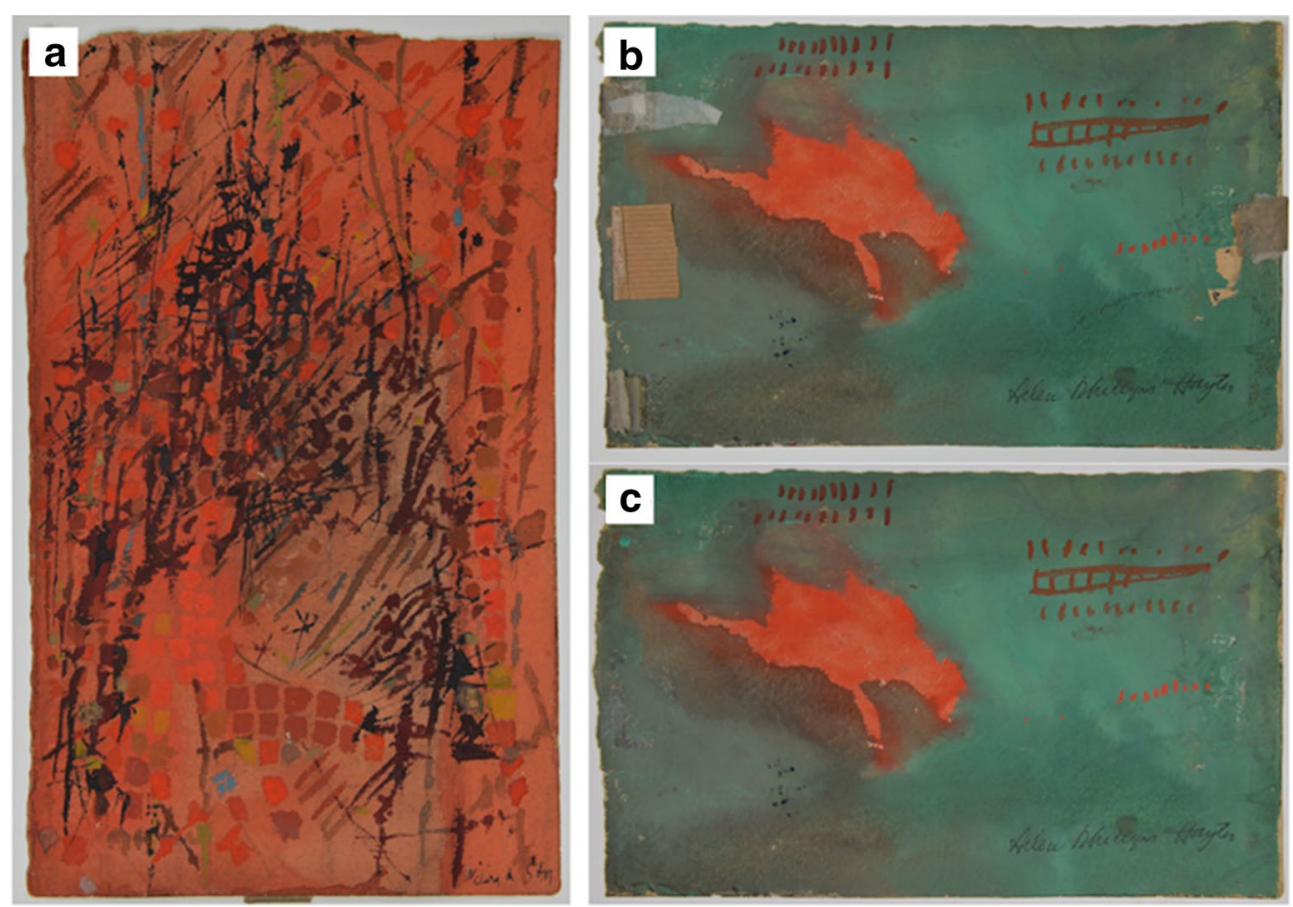

Fig. 9 a Maria Helena Vieira da Silva tempera on the recto side, and $\mathbf{b}$ Helen Philips Hayter watercolor on the verso side before PST removal; $\mathbf{c}$ Helen Philips Hayter watercolor after the PST removal using a pHEMA/PVP-EAPC gel. Image readapted from Bonelli et al. Restoration of paper artworks with microemulsions confined in hydrogels for safe and efficient removal of adhesive tapes. PNAS. 2018 Jun;1 15(23):5932-5937

swelled the adhesive and softened the hinge, facilitating its removal with tweezers.

\section{Keith Haring}

The selected artwork (Untitled, 1983), belonging to the artist's Naples Series, had six PSTs (with polypropylene backings and either acrylate copolymers or natural rubber as adhesives) on the verso side, most likely old mounting hinges (see Fig. 10). These works, made with Haring's signature continuous line on a monochrome ground, carry a political, social and aesthetic message that would be compromised by media bleeding or local discoloration. The drawing, made using a black felt-tip pen, presents two disfiguring oxidized and yellowish areas on the upper edge, due to the penetration of the aged and discoloured PSTs adhesives. Preliminary micro-solubility tests had indicated that the original ink is highly sensitive to most solvents used in PST removal, but substantially inert to DEC. The removal of the six PSTs was carried out in two steps [18]. First, PEMA-DEC gels were placed onto the PSTs for a maximum of $30 \mathrm{~min}$ (in this case the gels were covered with a polyester film in order to further reduce solvent evaporation through longer applications); then, the detached backings were simply removed with tweezers, with no damage or alteration of the inked artwork. After the removal of the backings, gentle mechanical action (using a crepe-rubber eraser, a common procedure for graphic arts) was combined with the use of DEC, controlled by means of a vacuum suction table, in order to remove the deeply ingrained adhesive residues.

\section{Pierre Buraglio}

In the painted collage Les très riches heures de P.B. (1982), Buraglio arranges strips of thick brown packing tape (BT, with transparent polypropylene backing and brown acrylic-based adhesive) over two adjoining spreads of newspaper, scribbled over and embellished with colored pencil (see Fig. 11). In this artwork, the artist transformed humdrum newsprint into a window view, the "scene one" of art-making and ornamented daily life. This case study represents a different conservation scenario than the artworks discussed in the previous sections. In fact, in this case there was no need of removing the PSTs, since they are integral part of the collage; however, the aged PSTs were partially delaminated and detackified, likely owing to the high porosity of the paper substrate, to the presence of artistic media between paper and the PSTs, and possibly to uneven pressure made by the artist at the time of PSTs application. Where delamination occurred, the PSTs lifted from the substrate, and there was the need to re-adhere the tapes to the brown adhesive layer and to 

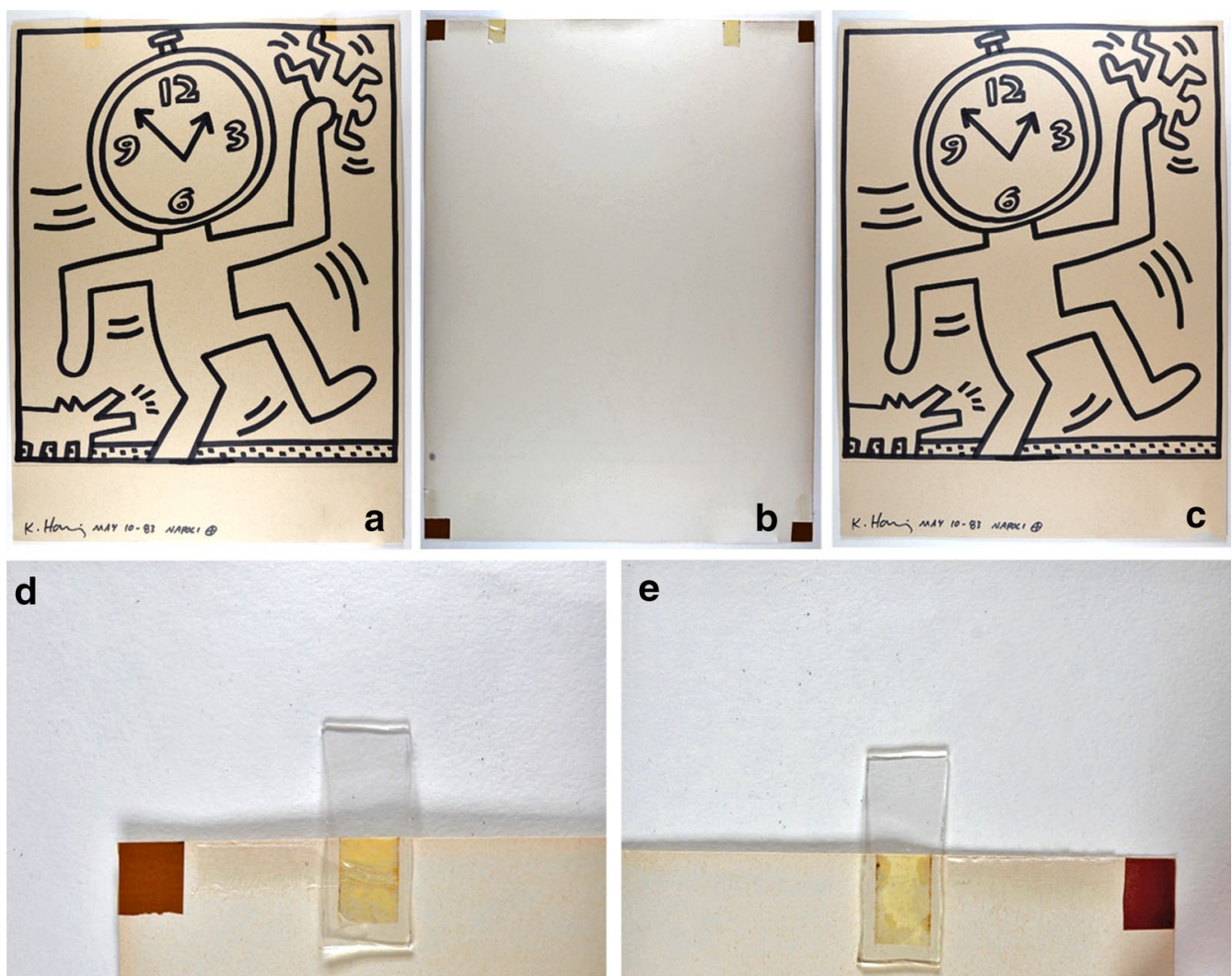

Fig. 10 a Keith Haring drawing before PST removal, $\mathbf{b}$ verso side with six PSTs, $\mathbf{c}$ general view of the drawing after the removal, $\mathbf{d}$ and $\mathbf{e}$ details of the application of the PEMA gels loaded with DEC on the tapes

the paper substrate, so as to recover the original aesthetic look of the artwork.

The complete removal of the PSTs followed by their repositioning with a new adhesive was not possible because it is extremely risky to remove tapes of such dimensions (about $80 \mathrm{~cm}$ ) without removing part of the graphic media, or without deforming the tapes. Instead, a practical and effective solution was to use a PEMA organogel loaded with DEC which, as previously illustrated, allows the swelling and reactivation of the adhesive in short application times (5 $\mathrm{min})$; in this case, after contact with the PEMA-DEC gel, the "re-activated" PSTs were put under weight (rather than removed), leading to the re-adhesion and setting of the delaminated layers. This intervention represents a new applicative mode of the PEMA-DEC gels, showing that these are versatile and adaptable tools.

\section{Conclusions}

This contribution provided an overview and expanded on the application of two recently developed methodologies for the removal of PSTs from paper artifacts, which employ confining systems and "green" cleaning fluids as alternatives to non-confined solvents traditionally used in the restoration practice. New cleaning case studies were introduced to test the versatility and applicability of the two methods in challenging conditions, which led to an extensive assessment of their full potential and to advancement in the use of these methodologies. The two methodologies are complementary, in that they are based on the confinement of, respectively, an aqueous $\mathrm{o} / \mathrm{w}$ nanostructured fluid in a hydrogel (pHEMA/PVPEAPC) and an organic solvent in an organogel (PEMADEC), allowing to target different types of PSTs. Namely, confocal microscopy measurements confirmed that the PEMA-DEC system is able to release the solvent at controlled rate through polypropylene and polyvinylchloride backings, complementing the ability of pHEMA/PVPEAPC to exchange the nanostructured fluid through more hydrophilic (or less hydrophobic) backings such as cellulose and cellulose acetate. In both cases, the retentiveness of the gels is fundamental to grant the penetration of fluids through the backing layer of PSTs, and the controlled swelling and softening of the adhesive layers underneath the backings, allowing the safe removal of PSTs without undesired bleeding of artistic media, 

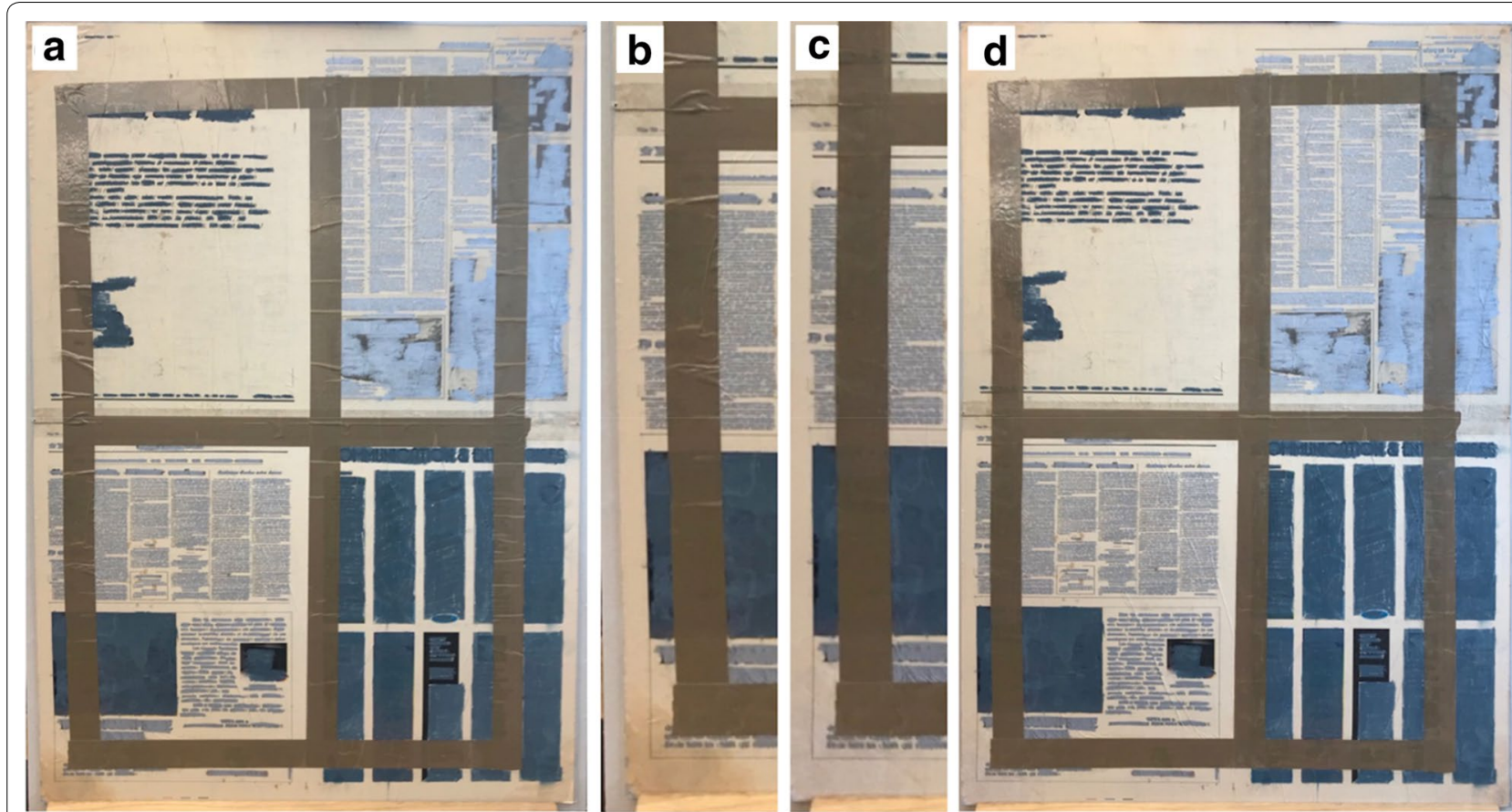

Fig. 11 a Les très riches heures de P.B. (1982) by Pierre Buraglio, before the consolidation and re-adhesion of the wrinkled and delaminated PSTs; b detail of the lower half of the left side before treatment; $\mathbf{c}$ detail of the lower half of the left side after treatment, showing the re-adhesion of the tapes; $\mathbf{d}$ general view after the reactivation of the original PST adhesives using PEMA-DEC gels

transport of solubilized matter through the porous matrix of paper artworks, or fast cleaning fluids evaporation, i.e. typical issues when non-confined solvents are used. Namely, no adhesive residual, no tidelines, no media bleeding, no skinning of the paper substrate nor dimensional instability were noticed at the surface of the paper models. In some cases, extraction and migration of the dyes in the EAPC-loaded gel was noticed on inked paper mock-ups, but without uncontrolled spreading of the dyes across the paper surface. 2D FTIR Imaging confirmed that the application of the PEMA-DEC gel, coupled with gentle mechanical action on the swollen/ softened adhesive layer, leads to substantial removal of the adhesive down to the micron scale.

When moving from models to real artworks, it is clear that confinement in a gel of the EAPC fluid or of DEC is key for conservation treatment. Confinement enables the control of release, penetration and lateral spreading of the liquid phase, minimizing the contact with sensitive components of the artwork and limiting the possible movements of the inks. Several combinations of PSTs backings and adhesives were addressed, on different types of artistic media, so as to provide a complete framework. In cases where the PSTs are part of the original artistic materials, the controlled release of fluids by the gels was useful to gradually swell the aged and detackified adhesives, "reactivating" the adhesive layer, which can then be fixed to the substrate simply applying a weight for a short time. The presented case studies demonstrate that a highly versatile tool is available to conservators, guaranteeing complete control of the removing fluids during all of the steps required for PST removal from paper artworks.

This confinement-based methodology ensures the achievement of unprecedented safe and efficient removal of PSTs from paper artworks without affecting the chemical, physical or optical properties of the drawing. Finally, it must be noticed that that the reagents and materials used for the preparation of these systems are affordable and feasibly accessible. Besides, commercial multipurpose formulations of p(HEMA)/ PVP-based hydrogels and o/w nanostructured fluids for the cleaning of works of art are commercially available to restorers worldwide.

\section{Acknowledgements}

The authors would like to acknowledge all NANORESTART partners for useful discussion.

\section{Authors' contributions}

AM, PB conceived the research for PST removal from paper; AM, PB and RG designed the research; AM, PF, CM, DB, DC, NB and RG performed research; $\mathrm{PF}, \mathrm{CM}, \mathrm{DC}$ and NB analysed data; AM wrote the paper. All authors read and approved the final manuscript. 


\section{Funding}

This research has received funding from the European Union (NANORESTART project: nanomaterials for the restoration of works of art), Horizon 2020 research and innovation program, Grant H2020-NMP-21-2014/646063. Consorzio Interuniversitario per lo Sviluppo dei Sistemi a grande Interfase (CSGI) is also acknowledged for financial support.

\section{Availability of data and materials}

All the available data have been included in the article.

\section{Ethics approval and consent to participate}

Not applicable.

\section{Consent for publication}

Not applicable.

\section{Competing interests}

The authors declare no conflict of interest.

\section{Author details}

${ }^{1}$ Paper Conservator, 75009 Paris, France. ${ }^{2}$ Department of Chemistry and Consorzio Interuniversitario per lo Sviluppo dei Sistemi a Grande Interfase (CSGI), University of Florence, 50019 Florence, Italy.

Received: 11 February 2020 Accepted: 23 April 2020

Published online: 29 April 2020

\section{References}

1. O'Loughlin EM. Pressure sensitive tapes and our cultural heritage. TechTech Semin Proc. PSTC; 2001. p. 223-232.

2. Smith MA, Jones NMM, Page SL, Dirda MP. Pressure-sensitive tape and techniques for its removal from paper. J Am Inst Conserv. 1984:23:101-13.

3. Skeist I, editor. Handbook of adhesives. 3rd ed. US: Springer; 1990.

4. Satas D. Handbook of pressure sensitive adhesive technology. US: Springer; 1989

5. PSTC-10. Peel adhesion of pressure sensitive tape. Test Method Press Sensitive Adhes Tapes. 15th ed. Northbrook, IL: Pressure Sensitive Tape Council; 2007.

6. Chelazzi D, Giorgi R, Baglioni P. Microemulsions, micelles, and functional gels: how colloids and soft matter preserve works of art. Angew Chem Int Ed Engl. 2018;57:7296-303.

7. Baglioni M, Montis C, Chelazzi D, Giorgi R, Berti D, Baglioni P. Polymer film dewetting by water/surfactant/good-solvent mixtures: a mechanistic insight and its implications for the conservation of cultural heritage. Angew Chem Int Ed Engl. 2018;57:7355-9.

8. Bonelli N, Chelazzi D, Baglioni M, Giorgi R, Baglioni P. Confined aqueous media for the cleaning of cultural heritage: innovative gels and amphiphile-based nanofluids. In: Dillmann P, Bellot-Gurlet L, Nenner I, editors. Nanosci Cult Herit. Paris: Atlantis Press; 2016. p. 283-311.

9. Mazzuca C, Poggi G, Bonelli N, Micheli L, Baglioni P, Palleschi A. Innovative chemical gels meet enzymes: a smart combination for cleaning paper artworks. J Colloid Interface Sci. 2017;502:153-64.

10. Baglioni M, Bartoletti A, Bozec L, Chelazzi D, Giorgi R, Odlyha M, et al. Nanomaterials for the cleaning and $\mathrm{pH}$ adjustment of vegetabletanned leather. Appl Phys A. 2016;122:114.

11. Capello C, Fischer U, Hungerbühler K. What is a green solvent? a comprehensive framework for the environmental assessment of solvents. Green Chem. 2007;9:927-34.

12. Mizia F, Notari M, Rivetti F, Romano U, Zecchini C. Carbonati alchilici: solventi della nuova generazione. Chim E Ind- Milano. 2001;83:47-54

13. Delledonne D, Rivetti F, Romano U. Developments in the production and application of dimethylcarbonate. Appl Catal Gen. 2001:221:241-51.

14. Wang D, Yang B, Zhai X, Zhou L. Synthesis of diethyl carbonate by catalytic alcoholysis of urea. Fuel Process Technol. 2007:88:807-12.

15. Baglioni M, Berti D, Teixeira J, Giorgi R, Baglioni P. Nanostructured surfactant-based systems for the removal of polymers from wall paintings: a small-angle neutron scattering study. Langmuir ACS J Surf Colloids. 2012;28:15193-202.

16. Domingues JAL, Bonelli N, Giorgi R, Fratini E, Gorel F, Baglioni P. innovative hydrogels based on semi-interpenetrating $\mathrm{p}$ (HEMA)/PVP networks for the cleaning of water-sensitive cultural heritage artifacts. Langmuir. 2013;29:2746-55

17. Baglioni M, Domingues JAL, Carretti E, Fratini E, Chelazzi D, Giorgi R, et al. complex fluids confined into semi-interpenetrated chemical hydrogels for the cleaning of classic art: a rheological and saxs study. ACS Appl Mater Interfaces. 2018;10:19162-72.

18. Ferrari P, Chelazzi D, Bonelli N, Mirabile A, Giorgi R, Baglioni P. Alkyl carbonate solvents confined in poly (ethyl methacrylate) organogels for the removal of pressure sensitive tapes (PSTs) from contemporary drawings. J Cult Herit. 2018;34:227-36.

19. Baglioni P, Bonelli N, Chelazzi D, Chevalier A, Dei L, Domingues J, et al. Organogel formulations for the cleaning of easel paintings. Appl Phys A. 2015;121:857-68.

20. Saviello D, Trabace M, Alyami A, Mirabile A, Giorgi R, Baglioni P, et al. A combined surface enhanced raman spectroscopy (SERS)/UV-Vis approach for the investigation of dye content in commercial felt tip pens inks. Talanta. 2018;181:448-53.

21. Saviello D, Gioia AD, Turenne P-I, Trabace M, Giorgi R, Mirabile A, et al. Handheld surface-enhanced Raman scattering identification of dye chemical composition in felt-tip pen drawings. J Raman Spectrosc. 2019;50:222-31

22. TAPPI. Hydrogen ion concentration $(\mathrm{pH})$ of paper extracts (cold extraction method), TAPPI Press. TAPPI Press; 2002.

23. Giorgi R, Chelazzi D, Baglioni P. Nanoparticles of calcium hydroxide for wood conservation. The deacidification of the Vasa warship. Langmuir. $2005 ; 21: 10743-8$

24. Gorassini A, Adami G, Calvini P, Giacomello A. ATR-FTIR characterization of old pressure sensitive adhesive tapes in historic papers. J Cult Herit. 2016:21:775-85.

25. Zięba-Palus J. The usefulness of infrared spectroscopy in examinations of adhesive tapes for forensic purposes. Forensic Sci Criminol [Internet]. 2017 [cited 2018 Mar 22];2. http://oatext.com/The-usefulness -of-infrared-spectroscopy-in-examinations-of-adhesive-tapes-for-foren sic-purposes.php.

26. Litvinov VM, De PP. Spectroscopy of rubbers and rubbery materials. Smithers Rapra Technology. 2002.

27. Rolere S, Liengprayoon S, Vaysse L, Sainte-Beuve J, Bonfils F. Investigating natural rubber composition with Fourier Transform Infrared (FT-IR) spectroscopy: a rapid and non-destructive method to determine both protein and lipid contents simultaneously. Polym Test. 2015;43:83-93.

28. Munteanu SB, Vasile C. Spectral and thermal characterization of styrene-butadiene copolymers with different architectures. J Optoelectron Adv Mater. 2005:7:3135-48.

29. Trafela T, Strlič M, Kolar J, Lichtblau DA, Anders M, Mencigar DP, et al. Nondestructive analysis and dating of historical paper based on IR spectroscopy and chemometric data evaluation. Anal Chem. 2007:79:6319-23.

30. Giachet MT, Schilling M, McCormick K, Mazurek J, Richardson E, Khanjian $\mathrm{H}_{\text {, et }}$ al. Assessment of the composition and condition of animation cels made from cellulose acetate. Polym Degrad Stab. 2014;107:223-30.

31. Stromberg RR, Straus S, Achhammer BG. Infrared spectra of thermally degraded poly(vinyl-chloride). J Res Natl Bur Stand. 1958;60:147.

32. Rajendran S, Prabhu MR, Rani MU. Ionic conduction in poly(vinyl chloride)/poly(ethyl methacrylate)-based polymer blend electrolytes complexed with different lithium salts. J Power Sources. 2008;180:880-3.

33. Bonelli N, Montis C, Mirabile A, Berti D, Baglioni P. Restoration of paper artworks with microemulsions confined in hydrogels for safe and efficient removal of adhesive tapes. Proc Natl Acad Sci. 2018;115:5932-7.

34. Chan KLA, Kazarian SG. Detection of trace materials with Fourier transform infrared spectroscopy using a multi-channel detector. Analyst. 2006:131:126-31.

35. Ellis MH. Drawings in fibre-tipped pen : new conservation challenges. Mod Works Mod Probl Conf Pap. 1994:114.

36. Pfingstag G. Colorants in inks for writing, drawing and marking. J Soc Dye Colour. 1993;109:188-92. 
37. Sharma MK, editor. Surface phenomena and additives in water-based coatings and printing technology. US: Springer; 1991.

38. Laden P, editor. Chemistry and technology of water based inks. Netherlands: Springer; 1997.

39. Ponting KG. A dictionary of dyes and dyeing. 1982.

40. Feller RL. Felt-tipped markers and the need for standards of lightfastness for artists' colorants. Bull Am Group Int Inst Conserv Hist Artist Works. 1967;8:24-6.

\section{Publisher's Note}

Springer Nature remains neutral with regard to jurisdictional claims in published maps and institutional affiliations.

\section{Submit your manuscript to a SpringerOpen ${ }^{\circ}$ journal and benefit from:}

- Convenient online submission

- Rigorous peer review

- Open access: articles freely available online

- High visibility within the field

- Retaining the copyright to your article

Submit your next manuscript at $\boldsymbol{\nabla}$ springeropen.com 